\title{
Grand challenges in psychosomatic research
}

\section{Ripu D. Jindal* and J. Richard Jennings}

University of Pittsburgh School of Medicine, Pittsburgh, PA, USA

*Correspondence: jindalr@upmc.edu

The link between emotion and disease has long fascinated mankind. Famous seventeen century British physician, Thomas Willis (1621-1675) saw diabetes as a consequence of sadness or long sorrow (Willis, 1971). Though better known for describing what eventually became known as the "Circle of Willis", he provided a fairly comprehensive description of the role of nervous system in disease (Encyclopædia Britannica, 2010). Willis may not have been the first to see the link, but his account stands out for its sophistication. In subsequent years and centuries, psychosomatic medicine has fallen in and out of favor many times. Depending on whom we ask, and what we focus on, we are currently witnessing exciting and challenging times for psychosomatic research.

Despite decades of work, a key question in psychosomatic research remains: do psychiatric disorders cause or contribute to physical disease such as heart disease, diabetes and asthma? And given the treatments that we have, a second question is: does timely and optimum treatment of the psychiatric disorders prevent, arrest or roll back the progression of physical disease? As brain was shown to influence systemic physiology in health, as well as in disease, the impact of cognition and emotion, and not just psychiatric illness, on general physical health became an important line of investigation. Indeed, there is more to psychosomatic research than just psychosomatic medicine. With the new interest in positive psychology, the impact "positive emotional states" such as equanimity, level-headedness and congruence is also an important topic for investigation.

Among the positive developments are many exciting findings from neuroimaging studies as well as the promise of genetic studies. Neuroimaging has put "brain" back at the center of the psychosomatic medicine (Lane et al., 2009). Consequently, models in "mind body" medicine are becoming more elegant and plausible, and include diverse variables such as, mental/psychological/ behavioral states and traits; brain; infor- mation transfer systems such as autonomic nervous system, endocrine, immune; and end organ functioning (Lane et al., 2009). Imaging studies suggest that brain has a role in a wide variety of systemic disorders such as irritable bowel syndrome, conversion disorder, asthma, fibromyalgia and pain disorder (Lane and Wager, 2009). The evidence of such a role is not surprising, but what is striking is the amount of overlap in the findings among these seemingly diverse conditions. Most of this overlap is apparent in the fronto-limbic structures, such as the prefrontal cortex, insula, cingulate, orbitofrontal cortex, subcortical areas such as amygdala, ventral striatum and hippocampus. These very structures, notably, also seem to have a role in regulating immune function, autonomic and endocrine systems (Lane and Wager, 2009; McEwen and Gianaros, 2010).

With the gradual decrease in the cost of conducting neuroimaging studies, it is becoming easier to conduct studies that can establish potentially causal or mediational relationships.

Combining neuroimaging and genetics (Hariri and Weinberger, 2003) has also begun to pay dividends. A recent study examined the impact of a polymorphism within the catechol-O-methyltransferase (COMT) gene, the Val(108/158)Met polymorphism, in conjunction with structural and functional neuroimaging; results suggest that the COMT Met allele modulates neural substrates of negative versus positive emotion processing, and may contribute to negativity bias, i.e., tendency to perceive danger rather than reward (Williams et al., 2010). The same group of investigators had earlier demonstrated that early life stress led to greater negativity bias in those with a variant of serotonin transporter linked promoter region (5-HTT-LPR Short allele; Williams et al., 2009). Since negativity bias is generally held as predisposing to anxiety and depression, this line of investigation can potentially establish polymorphisms with the COMT and 5-HTT-LPR genes, as well as identify other genes as predisposing factors in these psychiatric disorders. Aside from elucidating the pathophysiology of psychiatric disorders, this line of work may help focus the preventative effort to those at the greatest risk. Since individuals with the short allele of 5HTT-LPR also show more prominent positron emission tomography findings in response to colorectal distention, this particular polymorphism may also have implications for psychosomatic medicine (Fukudo et al., 2009).

The findings from basic research, such as the growing understanding of the link between autonomic system and the immune system, also strengthen the case for psychosomatic research (Oke and Tracey, 2009). Till now, it was hard to ascertain the utility and underlying mechanism for complementary and alternative medical treatments. But over the past decade, it became known that immune system can be regulated by the vagus nerve (Tracey, 2007). Simultaneously, the role of immune system in the pathogenesis of atherosclerosis, type 2 diabetes, Alzheimer disease, rheumatoid arthritis, inflammatory bowel disease, multiple sclerosis, and sepsis also became clearer (Klover et al., 2005; Plomgaard et al., 2005; Popa et al., 2007). Now, the evidence that a variety of interventions such as hypnosis, biofeedback, behavioral modification, cognitive and relaxation therapies can stimulate the vagus nerve (Lehrer et al., 2003; Peng et al., 2004; Nolan et al., 2010) sets the stage for studies that examine whether these interventions can also impact the immune system and thereby, alleviate the growing list of disorders believed to have a significant inflammatory component (Oke and Tracey, 2009).

Despite the positives, many challenges remain. Chiefly, translational research is difficult to conduct, especially when one aims to examine the impact of an intervention in a disease with long gestation period. Greater understanding of the predictors and surrogate markers certainly helps. For example, long-term studies that established insulin 
resistance as a predictor of type 2 diabetes help in designing diabetes prevention trials that can potentially demonstrate, in a timely manner, the superiority of one form of intervention over the others. But, not knowing all the mediators and moderators of response makes it impossible to conduct truly randomized trials. For example, we have learned to control for physical activity levels and dietary calorie count. But until recently, we did not know enough about the role of omega-3 fatty acids in depression (Appleton et al., 2010) and chronic diseases, such as diabetes and heart disease (Mozaffarian et al., 2006; Surette, 2008; Tavazzi et al., 2008), to control for dietary amounts of omega-3 fatty acids. Similarly, we have only begun to understand the role of genetic polymorphism such as those within the COMT and BDNF genes in pathogenesis of psychiatric and physical disease. One wonders if the failure to control for dietary content and genetic polymorphism in the participants contributed to our failure to consistently detect improvement in cardiac outcomes with successful treatment of depression even though depression has been all but proven a prognostic variable.

If we go by the number of published studies, the field of psychiatric genetics seemed to have exploded. However, the associations detected in such studies are small and often do not withstand statistical adjustment for multiple comparisons. Furthermore, neuropsychiatric disorders are characterized by so much heterogeneity that most unrelated patients seem to have a different genetic cause (McClellan and King, 2010a). Though, collectively rare mutations are detected in a substantial proportion of patients, no single locus of mutations explains more than $1-2 \%$ of cases (Purcell et al., 2009; McClellan and King, 2010a). Another challenge is that most disease causing mutations seem to be "new", i.e., either appearing for the first time ( $d e$ novo) or have occurred in recent generations (McClellan and King, 2010b).

Learning new brain pathways, central and peripheral, between emotion processing and end organs with known roles in pathogenesis of physical disease is exciting indeed. But equally important, though perhaps less interesting, is understanding the impact of physical illness, and chosen interventions, on psychological functioning. Recent evidence implicates genetic factors in the greater prevalence of depression among cardiac patients (McCaffery et al., 2009). The predictive value of a genetic polymorphism related to endothelial dysfunction in the emergence of depressive symptoms amongst cardiac patients suggests that endothelial dysfunction could be a novel mechanism for the onset of depression. The development of depressive symptoms in a subset of patients receiving interferon-alpha treatment has similarly led to greater understanding of the role of serotonin transporter polymorphism in the development of depression (Lotrich et al., 2009).

Apart from the physical disease itself, the impact of chosen interventions on psychological functioning is also an important pillar of psychosomatic research. This "pillar" supplies the information that the patients and their providers need to make truly informed choices. For example, intrusiveness of undergoing regular dialyses in the life and psychological functioning of a given individual is quite different from what is experienced after a renal transplant (Devins et al., 1990). With the stated goal of developing personalized care, systematic examination of psychological impact in individual patients would make it easier to find a better goodness of fit. With ever growing list of treatment options, as well as the option of treating versus not treating, this line of investigation will continue to be important.

Another line of investigation addresses somatoform disorders. Moves are afoot to recast the nomenclature (Dimsdale and Creed, 2009). The current terminology faces criticism: patients invariably do not like the consequent "labeling" and primary care physicians, who see a majority of these patients, find the terminology difficult to understand. The contemporary terminology also creates an unfortunate divide between physical and mental disease. Without doubt, there is a merit in viewing somatoform disorders simply as those characterized by predominant somatic symptoms that result in significant distress or dysfunction (Dimsdale and Creed, 2009). Among the changes under consideration, diagnosis of somatization disorder, undifferentiated somatoform disorder, hypochondriasis, and pain disorder could be clubbed together as somatic symptom disorders. Recasting the nomenclature will hopefully stimulate new research and new understanding. As it is, much of the available literature on these disorders is old.

Though, historically, psychosomatic research has not lived up to its full promise, the new generation of studies provides a strong reason for new optimism. History as we know, often teaches us wrong lessons. Our challenge is to win back old "believers" as we attract new ones. There will be a continued need to disseminate emerging findings among the general public and our colleagues in other disciplines. Given strong headwinds such as the recent economic downturn, convincing funding agencies to maintain, if not enhance, support for psychosomatic research will be a constant battle. A related challenge would be attract a constant supply of talented and motivated researchers to the field. The onus for knowledge dissemination is upon all of us; we at the Frontiers in Psychosomatic Research promise to do our part. With a few false starts and detours, we will get there!

\section{REFERENCES}

Appleton, K. M., Rogers, P. J., and Ness, A. R. (2010). Updated systematic review and meta-analysis of the effects of $\mathrm{n}$-3 long-chain polyunsaturated fatty acids on depressed mood. Am. J. Clin. Nutr. 91, 757-770.

Devins, G. M., Mandin, H., Hons, R. B., Burgess, E. D., Klassen, J., Taub, K., Schorr, S., Letourneau, P. K., and Buckle, S. (1990). Illness intrusiveness and quality of life in end-stage renal disease: comparison and stability across treatment modalities. Health Psychol. 9, 117-142.

Dimsdale, J., and Creed, F. (2009). The proposed diagnosis of somatic symptom disorders in DSM-V to replace somatoform disorders in DSM-IV - a preliminary report. J. Psychosom. Res. 66, 473-476.

Encyclopædia Britannica (2010). Retrieved July 04, 2010, from Encyclopædia Britannica Online.

Fukudo, S., Kanazawa, M., Mizuno T, Hamaguchi, T., Kano, M., Watanabe, S., Sagami, Y., Shoji, T., Endo, Y., Hongo, M., Itoyama, Y., Yanai, K., Tashiro, M., and Aoki, M. (2009). Impact of serotonin transporter gene polymorphism on brain activation by colorectal distention. Neuroimage 47, 946-951.

Hariri, A. R., and Weinberger, D. R. (2003). Imaging genomics. Br. Med. Bull. 65, 259-270.

Klover, P. J., Clementi, A. H., and Mooney, R. A. (2005) Interleukin-6 depletion selectively improves hepatic insulin action in obesity. Endocrinology 146, 3417-3427.

Lane, R. D., and Wager, T. D. (2009). The new field of Brain-Body Medicine: what have we learned and where are we headed? Neuroimage 47, 1135-1140.

Lane, R. D., Waldstein, S. R., Critchley, H. D., Derbyshire, S. W., Drossman, D. A., Wager, T. D., Schneiderman, N., Chesney, M.A., Jennings, J. R., Lovallo, W. R., Rose, R. M., Thayer, J. F., and Cameron, O. G. (2009). The rebirth of neuroscience in psychosomatic medicine, part II: clinical applications and implications for research. Psychosom. Med. 71, 135-151. 
Lehrer, P. M., Vaschillo, E., Vaschillo, B., Lu, S. E., Eckberg, D. L., Edelberg, R., Shih, W. J., Lin, Y., Kuusela, T. A., Tahvanainen, K. U., and Hamer, R. M. (2003). Heart rate variability biofeedback increases baroreflex gain and peak expiratory flow. Psychosom. Med. 65, 796-805.

Lotrich, F. E., Ferrell, R. E., Rabinovitz, M., and Pollock, B. G. (2009). Risk for depression during interferonalpha treatment is affected by the serotonin transporter polymorphism. Biol. Psychiatry 65, 344-348.

McCaffery, J. M., Duan, Q. L., Frasure-Smith, N., Barhdadi, A., Lesperance, F., Theroux, P., Rouleau, G. A., and Dube, M. P. (2009). Genetic predictors of depressive symptoms in cardiac patients. Am. J. Med. Genet. B Neuropsychiatr. Genet. 150B, 381-388.

McClellan, J., and King, M. C. (2010a). Genetic heterogeneity in human disease. Cell 141, 210-217.

McClellan, J., and King, M. C. (2010b). Genomic analysis of mental illness: a changing landscape. JAMA 303, 2523-2524.

McEwen, B. S., and Gianaros, P. J. (2010). Central role of the brain in stress and adaptation: links to socioeconomic status, health, and disease. Ann. N. Y. Acad. Sci. 1186, 190-222.

Mozaffarian, D., Prineas, R. J., Stein, P. K., and Siscovick, D.S. (2006). Dietary fish and n-3 fatty acid intake and cardiac electrocardiographic parameters in humans. J. Am. Coll. Cardiol. 48, 478-484.

Nolan, R. P., Floras, J. S., Harvey, P. J., Kamath, M. V., Picton, P. E., Chessex, C., Hiscock, N., Powell, J., Catt, M., Hendrickx, H., Talbot, D., and Chen, M.H. (2010). Behavioral neurocardiac training in hypertension: a randomized, controlled trial. Hypertension 55 1033-1039.

Oke, S. L., and Tracey, K. J. (2009). The inflammatory reflex and the role of complementary and alternative medical therapies. Ann. N. Y. Acad. Sci. 1172, 172-180.

Peng, C. K., Henry, I. C., Mietus, J. E., Hausdorff, J. M., Khalsa, G., Benson, H., and Goldberger, A. L. (2004) Heart rate dynamics during three forms of meditation. Int. J. Cardiol. 95, 19-27.

Plomgaard, P., Bouzakri, K., Krogh-Madsen, R., Mittendorfer, B., Zierath, J. R., and Pedersen, B. K. (2005). Tumor necrosis factor-alpha induces skeletal muscle insulin resistance in healthy human subjects via inhibition of Akt substrate 160 phosphorylation. Diabetes 54, 2939-2945.

Popa, C., Netea, M. G., van Riel, P. L., van der Meer, J. W. and Stalenhoef, A. F. (2007). The role of TNF-alpha in chronic inflammatory conditions, intermediary metabolism, and cardiovascular risk. J. Lipid Res. 48, 751-762.

Purcell, S. M., Wray, N. R., Stone, J. L., Visscher, P. M., O’Donovan, M. C., Sullivan, P. F., and Sklar, P. (2009). Common polygenic variation contributes to risk of schizophrenia and bipolar disorder. Nature 460, 748-752.

Surette, M.E. (2008). The science behind dietary omega-3 fatty acids. CMAJ 178, 177-180.

Tavazzi, L., Maggioni, A. P., Marchioli, R., Barlera, S., Franzosi, M. G., Latini, R., Lucci, D., Nicolosi, G. L., Porcu, M., and Tognoni, G. (2008). Effect of n-3 polyunsaturated fatty acids in patients with chronic heart failure (the GISSI-HF trial): a randomised, double-blind, placebo-controlled trial. Lancet 372 1223-1230.

Tracey, K. J. (2007). Physiology and immunology of the cholinergic antiinflammatory pathway. J. Clin. Invest. 117, 289-296.

Williams, L. M., Gatt, J. M., Schofield, P. R., Olivieri, G., Peduto, A., and Gordon, E. (2009). 'Negativity bias' in risk for depression and anxiety: brain-body fear circuitry correlates, 5-HTT-LPR and early life stress. Neuroimage 47, 804-814.

Williams, L. M., Gatt, J. M., Grieve, S. M., Dobson-Stone, C., Paul, R.H, Gordon, E., and Schofield, P. R. (2010) COMT Val(108/158)Met polymorphism effects on emotional brain function and negativity bias. Neuroimage. doi: 10.1016/j.neuroimage.2010.01.084. [Epub ahead of print].

Willis T. (1971). Diabetes: A Medical Odyssey. New York: Tuckahoe.

Received: 09 August 2010; accepted: 17 August 2010; published online: 24 September 2010.

Citation: Jindal RD and Jennings JR (2010) Grand challenges in psychosomatic research. Front. Psychiatry 1:131. doi: 10.3389/fpsyt.2010.00131

This article was submitted to Frontiers in Affective Disorders and Psychosomatic Research, a specialty of Frontiers in Psychiatry.

Copyright (c) 2010 Jindal and Jennings. This is an openaccess article subject to an exclusive license agreement between the authors and the Frontiers Research Foundation, which permits unrestricted use, distribution, and reproduction in any medium, provided the original authors and source are credited. 